\title{
Elemental Analysis of the Intrapulmonary Deposits in the Reported Autopsy Case of Aluminum Dust Lung Using Electron Probe X-ray Microanalysis
}

\author{
Junko Toki, Jiro Tateiwa* and Ryuei Maeda \\ Department of Pathology, Kansai Medical University, \\ Moriguchi, Osaka, Japan \\ *3rd Department of Int. Med., Kansai Med. Univ.
}

Key words : aluminum lung, electron probe $\mathrm{X}$-ray microanalysis

\section{General Consideration}

Since an antopsy case of aluminum dust lung was reported in detail by Goralewski ${ }^{6}$, a number of similar cases were reported in Germany, Canada and Great Britain. In Japan, the first autopsy case of aluminum dust lung was reported by Ueda et al. ${ }^{13}$ ) They demonstrated, using the Winter et al. method ${ }^{14)}$ applied to sections which were ashed at $500^{\circ} \mathrm{C}$, that aluminum present in the patient's lung was 4.5 times higher than that of control's lungs and that aluminum in the lung exhibited a bleaching property by chlorine gas, unlike carbon powder or hemosiderin. However, it did not show a positive reaction using the Okamoto et al. method ${ }^{12)}$ for aluminum possibly because of high affinity to protein. ${ }^{13)}$ Alternatively, Irwin's aluminum stain ${ }^{9)}$ failed to react with aluminum phagocytized by type 1 alveolar epithelial cells ${ }^{8)}$, possibly because of the extremely small size of the particles. Besides the mentioned case, over a period of more than 20 years since our previous report no autopsy case of aluminum dust lung was reported in Japan, though autopsy cases of bauxite dust lungs were seldom published in Japan.

Moreover, regarding animals, Mizuhira ${ }^{10}$ ) showed that both high and low peaks of $\mathrm{Si}$ and $\mathrm{Al}$, respectively, were obtained from silicotic lung specimens of a horse with a spot $\mathrm{X}$-ray pulse anlaysis (EDAX-707A or B).

Electron probe $\mathrm{X}$-ray microanalysis by a Hitachi $\mathrm{H}-500$ total system was applicated to the lung specimens from the previously reported aluminum dust lung.

\section{Clinical History}

The patient was a 32-year-old male worker in a factory where metallic powder for decorative purposes was manufactured. Examination of the metallic powder by Ueda et al. revealed that it 
contained 99. $3 \%$ metallic aluminum. After working for about 3 years and half, he complained of a respiratory distress with persistent cough. Since he was hospitalized, however, he got worse gradually and died on May 31, 1955, 3 year and 3 months after the onset of the disease.

\section{Gross appearances of lungs and pleura}

Pleura pulmonalis showed marked thickening throughout the pleural surface on both sides, densely adherent to the parietal pleura particularly noticeable in the interloblar area of the middle and upper lungs. The pulmonary parenchyma was hardened to a fair degree throughout the lung and cut surface revealed the whitish brown asbestos-like appearance. There were numerous emphysematous cavities or bullae of a grain to small bean size in each lobe of the left lung. The lumen of these cavities or bullae were empty and their internal surface was covered with smooth membrane.

\section{Histological findings of the lungs and pleura}

There was diffuse pulmonary fibrosis containing partial emphysematous bullae. In some parts there were mononuclear giant cells and dark-brown deposits of pigment. The interstitial tissue contained lumps of dark to brownish pigment, its greater part being phagocitized by macrophages. Some vascular walls seen in the fibrous tissue were markedly hyperplastic to the extent that their lumens were nearly obstructed. The alveolar structure of the normal-appearing lung parencyma indicated marked congestion.

\section{Main pathological and anatomical diagnosis}

1. Aluminum dust lung.

2. Hypertrophy of the right heart. (The heart weighed $305 \mathrm{~g}$ )

3. Congestion of the lungs. (weight, left $: 690 \mathrm{~g}$, right $: 730 \mathrm{~g}$ )

4. Pleural fibrotic adhesion of both sides.

\section{Materials and Methods}

After sufficient washing, formalin-fixed pulmonary tissues were immersed in osmium tetroxide, dehydrated with a series of graded alcohol and embedded in Epon. Ultrathin sections were cut and mounted on a copper grid. In order to identify pulmonary aluminum electron probe X-ray microanalysis was performed in unstained ultrathin sections by means of an energy dispersive X-ray microanalyzer attached to $\mathrm{H}-500$ (Hitachi H-500 total system --- H-500, H-5010, Kevex EDX). Elementary analysis was carried out in the scanning transmission (STEM) mode of the 
analytical electron microscope, with $75 \mathrm{KV}$ accelerating voltage, $5 \times 10^{-10}$ A specimen current on $\mathrm{Cu}$ grid, $20 \mathrm{sec}$ analytical time, using field scanning.

\section{Results}

Electron microscopy revealed that most of the dust particles in the interstitial macrophages contained electron-dense spheres with diameters ranging from 30 to $300 \mathrm{~nm}$ and osmiophilic hexagonal or plate-like crystals (Figs. 1, 2, 10 and 14). Electron probe X-ray microanalysis of the spheres in a $500 \mathrm{~nm}$-thick Epon section revealed a conspicuous peak for $\mathrm{K} \alpha$-line of aluminum at $1.49 \mathrm{KeV}$ (Figs. 4, 5, 11, 12 13, 15, 16 and 17). The distribution of the X-ray pulse of aluminum, as shown in Fig. 3, corresponded to the electron-dense granules ultrastructurally discerned in Fig. 2. Energy dispersive X-ray microanalysis of the osmiophilic hexagonal or platelike crystals in a similar section showed that the high and low energy peak were consistent with $\mathrm{K} \alpha$-lines produced by aluminum and silicon, respectively (Figs. 6 and 7). Furthermore, elementary analysis of needle-shaped crystals within a macrophage revealed that the low and high energy peaks were also consistent with $\mathrm{K} \alpha$-lines produced by aluminum and silicon, respectively (Fig. 8).

\section{Discussion}

It may be considered that the persistency of adequate formalin fixation in which the lung tissues which were fixed for more than 20 years, allowed the electron probe $\mathrm{X}$-ray microanalysis, after a suitable refixation.

It was reported that microprobe energy-dispersive $\mathrm{X}$-ray analysis of spheric electron-dense particles or crystalline structures contained in interstitial macrophages from various mineral dust lungs ${ }^{1)}$ and from an aluminum welder's lung showed the presence of predominant aluminum and a variety of minerals. In the present study similar findings were obtained. Alternatively, Chen et al. ${ }^{3)}$ reported that except for palladium from the coating in sample preparation, only aluminum was identified by energy dispersive $\mathrm{X}$-ray analysis of granulomas in pulmonary biopsy specimens from a patient showing pulmonary granulomatosis associated with aluminum inhalation. Moreover, it is noted that X-ray microanalysis of macrophages in the lungs from patients without pneumoconiosis revealed the presence of slight amounts of silicon, aluminum, iron and titanium. On the other hand, mineral kaolinite, a platy aluminum silicate of composition $\left(\mathrm{Al}_{2} \mathrm{O}_{3} \cdot 2 \mathrm{SiO}_{2} \cdot 2 \mathrm{H}_{2} \mathrm{O}\right)$ is one of the chief clay minerals. This material was evidenced ${ }^{2)}$ by energy-dispersive $\mathrm{X}$-ray analysis to be present in the phagosomes of pulmonary macrophages from cigarette smokers, since 2 energy peaks of nearly even intensity from microanalysis of such a structure are consis- 
tent with $\mathrm{K}$-lines produced by aluminum and silicon, respectively. In our study, microprobe energy-dispersive $\mathrm{X}$-ray analysis of needle-like inclusions dispersed in the cytoplasmic matrix of the interstitial macrophages revealed that these structures may be a kaolinite, since 2 energy peaks of nearly even intenstiy were consistent with $\mathrm{K}$-lines produced by aluminum and silicon, respectively. Brody et al. ${ }^{2)}$ reported that if a plate-like crystal is cut along the edge with microtome and viewed in section, it will appear linear to needle-like.

It should be emphasized that osmiophilic hexagonal or plate-like crystals found in the interstitial macrophages may be aluminum particles associated with silicate but not kaolinite, since energydispersive $\mathrm{X}$-ray analysis of the particles revealed a high and a low energy peak which are consistent with the $\mathrm{K}$-lines as already mentioned. Considering that metallic aluminum powder ${ }^{7}$, stamped aluminum powder ${ }^{4)}$ and an artificial aluminum silicate ${ }^{11)}$ all are capable of inducing pulmonary fibrosis in experimental animals exposed to these minerals, it is likely that osmiophilic plate-like crystals containing predominant amounts of aluminum dispersed in the cytoplasm of pulmonary interstitial macrophages play a role in the pulmonary diffuse fibrosis seen in this case.

Regarding bauxite consisting of predominant amounts of aluminate associated with silicate and other minerals, it was suggested that a long-term exposure to amorphous aluminum dust may play a dominant role in the diffuse fibrosis in bauxite-fume pneumoconiosis. ${ }^{15}$ )

That not all the workers exposed to aluminum dusts develop pulmonary fibrosis tends to support the notion that individual susceptibility or personal idiosyncrasy may be responsible for the development of such a lung disease in workers exposed to aluminum dust. ${ }^{3)}$ The above supposition might be favorable for explaining the fact that aluminum dust lung has not been reported except our report in Japan.

\section{Conclusion}

Electron probe $\mathrm{X}$-ray microanalysis of the lung specimens in the reported autopsy case of aluminum dust lung revealed that in interstitial macrophages particulate such as electron-dense spheres with diameter, in 30 to $300 \mathrm{~nm}$ range, contained abundant aluminum alone. Alternatively, osmiophilic plate-like crystals and needle-like inclusions were evidenced to contain both the aluminum and silicon, suggesting that these structures also may play a role in the pathogenesis of pulmonary fibrosis.

\section{Acknowledgement}

Our sincere thanks are due to Hitachi Co., Ltd. for its cooperation in electron probe X-ray microanalysis. 


\section{References}

1) Berry, J. P., Henoc, P., Galle, I. P. and Pariente, R. : Pulmonary mineral dust. Am. Path. 83, 427 456, 1976.

2) Brody, A. R. and Crighead, J.E. : Cytoplasmic inclusions in pulmonary macrophages of cigarette smokers. Lab. Invest. 32, 125 132, 1975,

3) Chen, Wei-Jen, Monnat, R. J., Chen Mei and Motte, N. K. : Aluminum induced pulmonary granulomatosis. Human Path. 9, 705 711, 1978.

4) Corrin, B. : Aluminum pneumoconiosis. II. Effect on the rat lung of intratracheal injections of stamped aluminum powders containing different lubricating agents and of a granular aluminum powder. Brit. J. Industr. Med. 20, 268 276, 1963.

5) Funahashi, A., Pintar, K. and Siegesmund, K. A. : Identification of foreign material in lung by energy dispersive $\mathrm{x}$-ray analysis. A new approach to sillicosis. Arch: Environ. Health 30, 285 289, 1975.

6) Goralewski, G. : Klinische und tierexperimentelle Studien zur Frage der Aluminium-Staublunge. Arch. Gewerbepath. 9, 676 688, 1939 ; Die Aluminiumlunge--- eine neue Gewerbeerkrankung. Z. ges. Inn. Med. 2, 665 673, 1947.

7) Gross, P., Harley, R.A. and deTreville, R. T. P. : Pulmonary reaction to metallic aluminum powders. Arch. Environ. Health 26, 227 236, 1973.

8) Herbert, A., Sterling, G., Abrahham, J. and Corrin, B: Desquamative interstitial pneumonia in an aluminum welder. Human Path. 13, 694 699, 1982.

9) Irwin, D. A. : The demonstration of aluminum in animal tissues. A. M. A. Arch. Indust. Health 12, 218 220, 1955.

10) Mizuhira, V. : Elemental analysis of biological specimens by electron probe $x$-ray analysis. Acta histochem. cytochem. 9, 69 87, 1976.

11) Musk, A. W. , Greville, H. W. and Tribe, A. E. : Pulmonary disease from occupational exposure to an artificial aluminum silicate used for cat litter. Brit. J. Indust. Med. 37, 367 372, 1980.

12) Okamoto, K. : The histochemiccal test-method of aluminum. Nihon Taishitsugaku Zasshi 13, 66 68, 1944. (in Japanese)

13) Ueda, M. , Mizoi, Y ., Maki, Z., Maeda, R. and Takada, R. : A case of aluminum dust lung. A necropsy report. Kobe J. Med. Sci. 4, 91 99, 1958.

14) Winter, O.B., Thrun, W. E. and Bird, 0.D. : The determination of aluminum in plants. 1. A study of the use of aurintricarboxylic acid for the coloriometric detemination of aluminum. J. Amer. Chem. Soc. 51, 2721 2731, 1927.

15) Wyatt, J.P. and Riddell, A.C.R. : The morphology of bauxite-fume pneumoconiosis. Am. J. Path. 25, 447 465, 1949. 


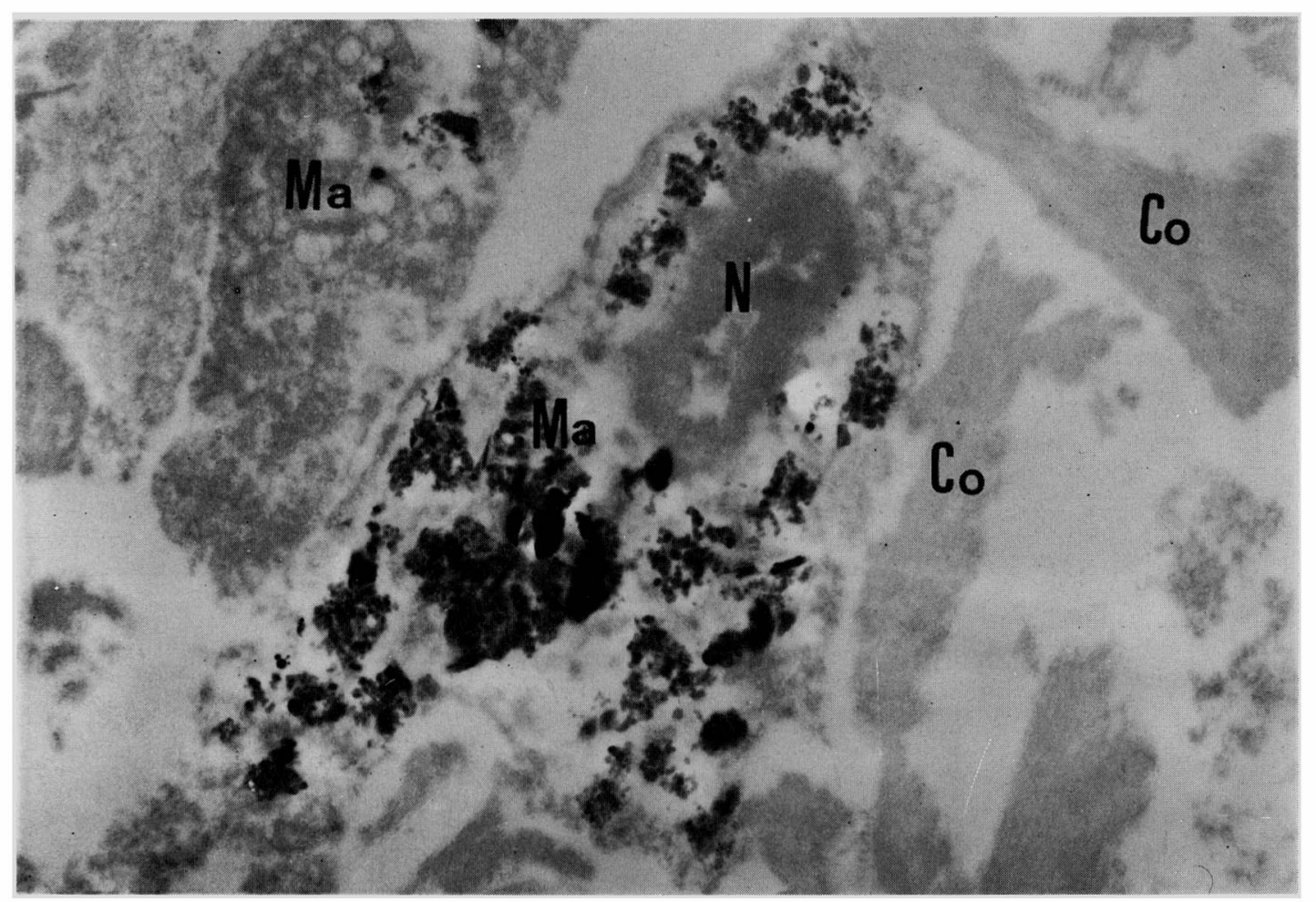

Fig. 1. Electron micrograph of a pulmonary interstitial macrophage including a lot of electron high-dense materials in its cytoplasm. $\mathrm{Ma}$ : macrophage, $\mathrm{N}$ : nucleus of the macrophage, $\mathrm{Co}_{0}$ : collagen fiber. Unstained. $\times 12,500$ 


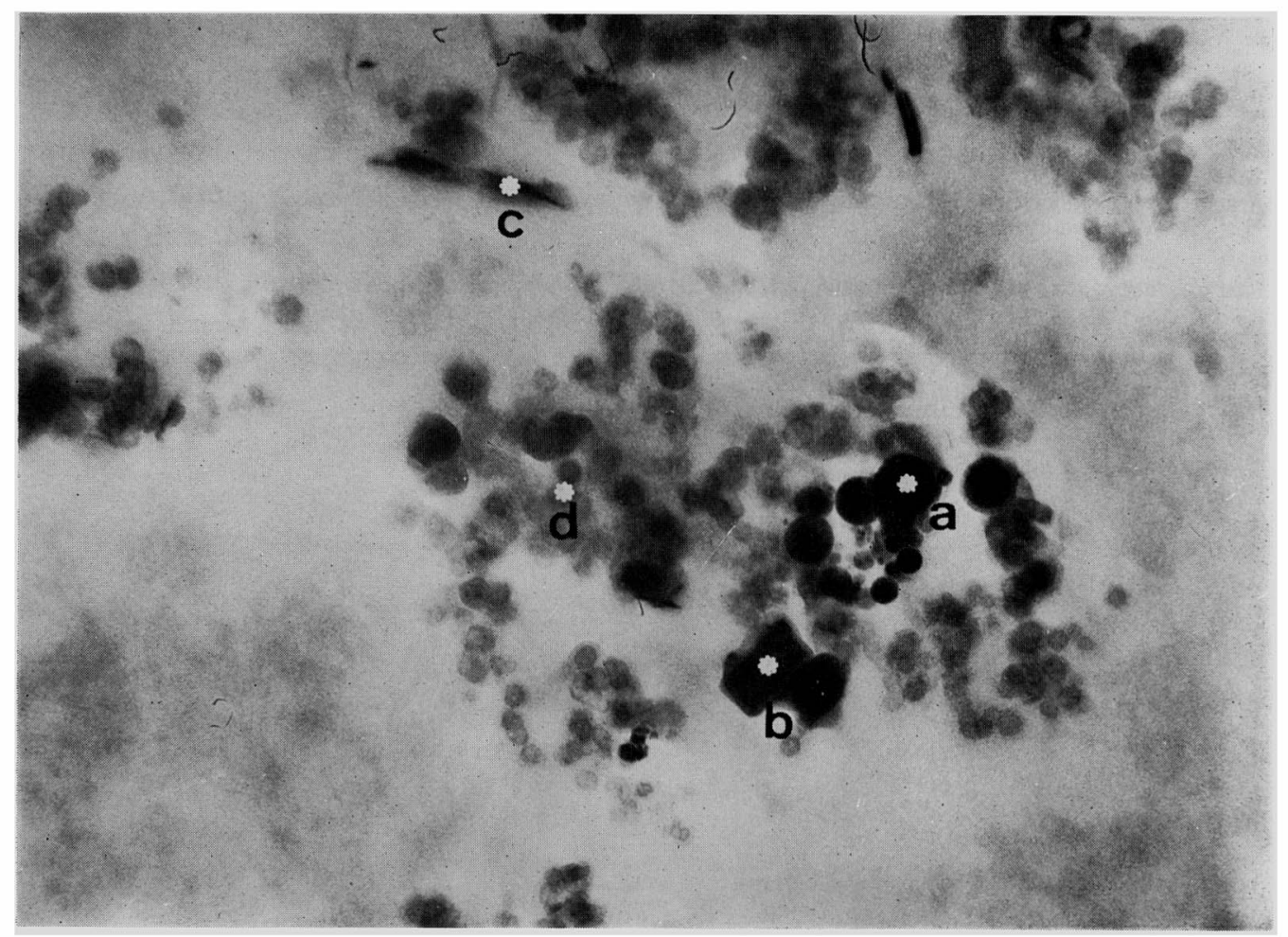

Fig. 2. A portion of the cytoplasm of a pulmonary interstitial macrophage with various electron-dense materials.

Electron probe X-ray analysis (Figs. 4-9) was made at four points (a-d) in this figure. Unstained. $\times 40,000$

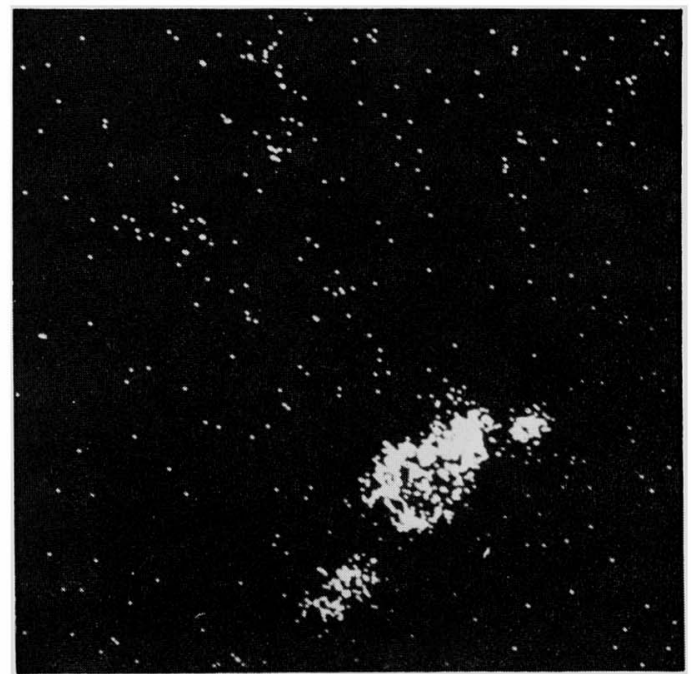

Fig. 3. The $X$-ray mapping of the same area as in Fig. 2 by characteristic pulse $\mathrm{X}$-ray image analysis $(\mathrm{Al}-\mathrm{K} \alpha)$. 


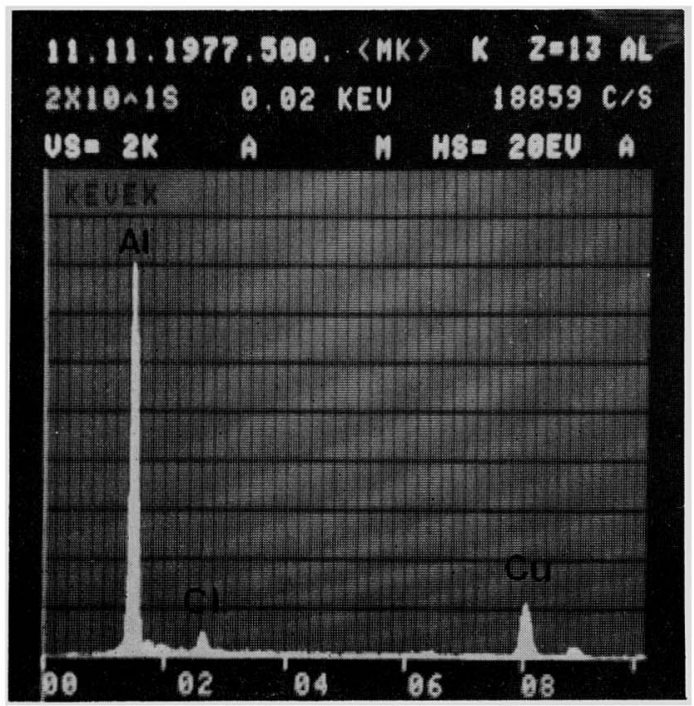

Fig. 4. Spot X-ray energy analysis of (a) in Fig. 2.

There is a definite peak at $1.49 \mathrm{KeV}$ consistent with the presence of aluminum. In addition to the aluminum peak, there are small peak for copper ( $\mathrm{K} \alpha$ at 8.04) and for chlorine $(\mathrm{K} \alpha$ at 2.62). The small $\mathrm{Cu}$ peak is from the grid and the small $\mathrm{Cl}$ peak from the Epon.

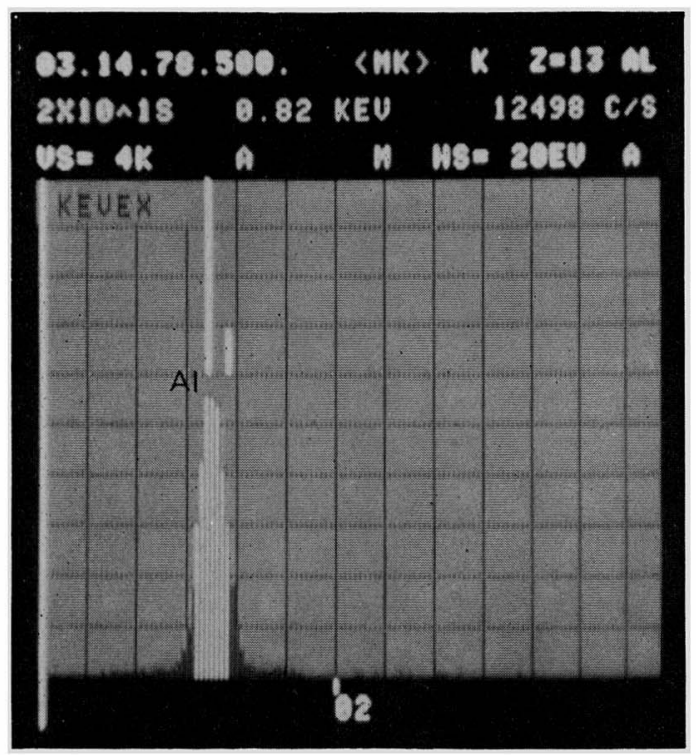

Fig. 5. Spot X-ray energy analysis of (a) in Fig. 2.

A distinct peak for aluminum ( $\mathrm{K} \alpha$ at 1.49$)$ is seen. This display spectrum was photographed at a wider holizontal scale than that in Fig. 4. 


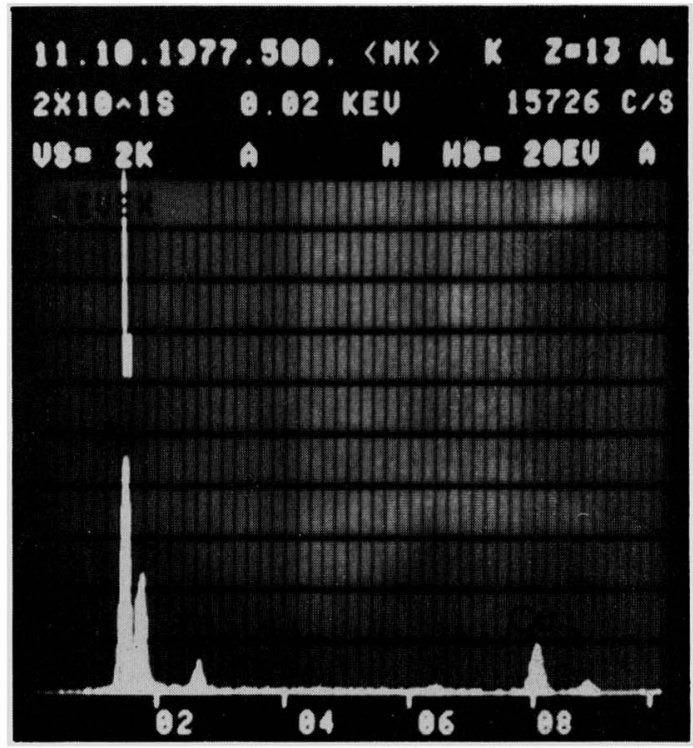

Fig. 6. Spot $X$-ray energy analysis of (b) in Fig. 2 .

Note two distinct peaks for aluminum ( $\mathrm{K} \alpha$ at 1.49$)$ and silicon $(\mathrm{K} \alpha$ at 1.73). The aluminum peak is higher than the silicon peak. The $\mathrm{Cu}$ peak ( $\mathrm{K} \alpha$ at 8.04$)$ is from the grid, and the $\mathrm{Cl}$ peak ( $\mathrm{K} \alpha$ at 2.62) from the Epon.

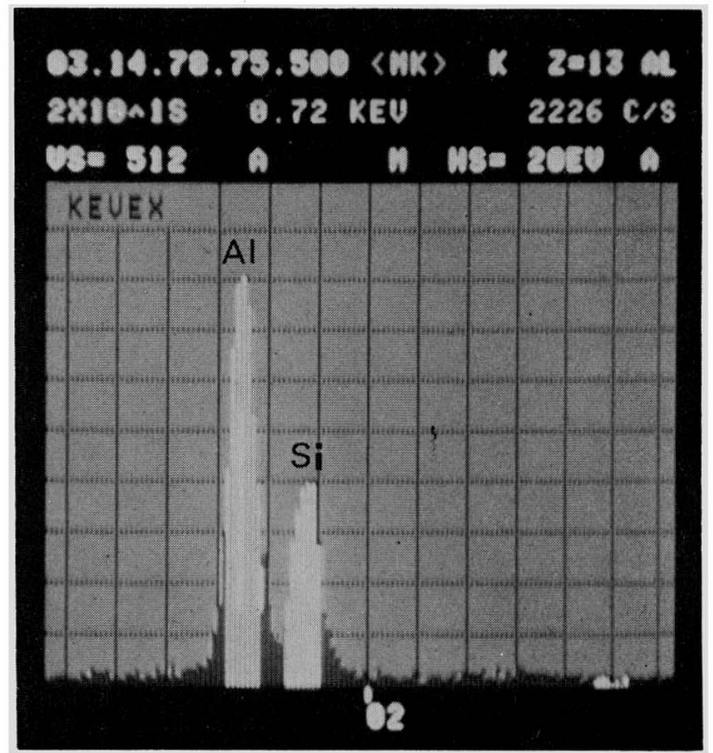

Fig. 7. Spot X-ray analysis of (b) in Fig. 2 .

This was photographed at a wider holizontal scale than that in Fig. 6 . 


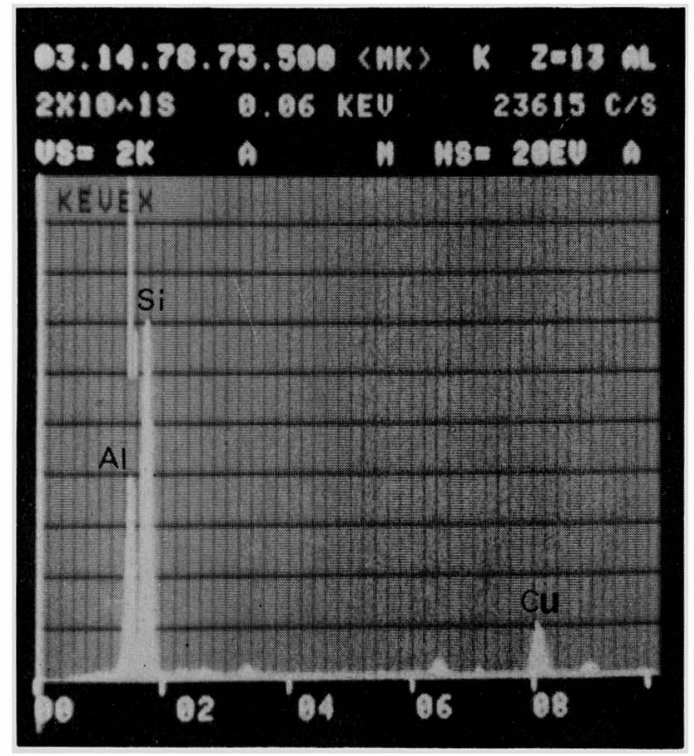

Fig. 8. Spot $X$-ray analysis of (c) in Fig. 2 .

Note 2 distinct peaks for aluminum ( $\mathrm{K} \alpha$ at 1.49$)$ and silicon ( $\mathrm{K} \alpha$ at 1.73). The aluminum peak is lower than the silicon peak. The $\mathrm{Cu}$ reak ( $\mathrm{K} \alpha$ at 8.04 ) is from the grid.

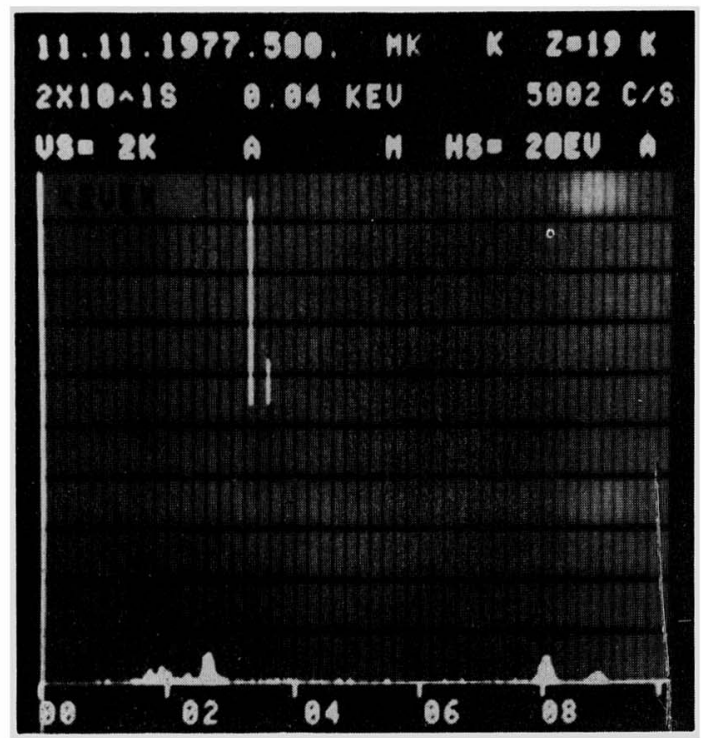

Fig. 9. Spot X-ray analysis of (d) in Fig. 2 .

No peak for aluminum is seen. The 2 recognizable peaks are those of $\mathrm{Cl}$ from the Epon and of $\mathrm{Cu}$ from the grid, respectively. 


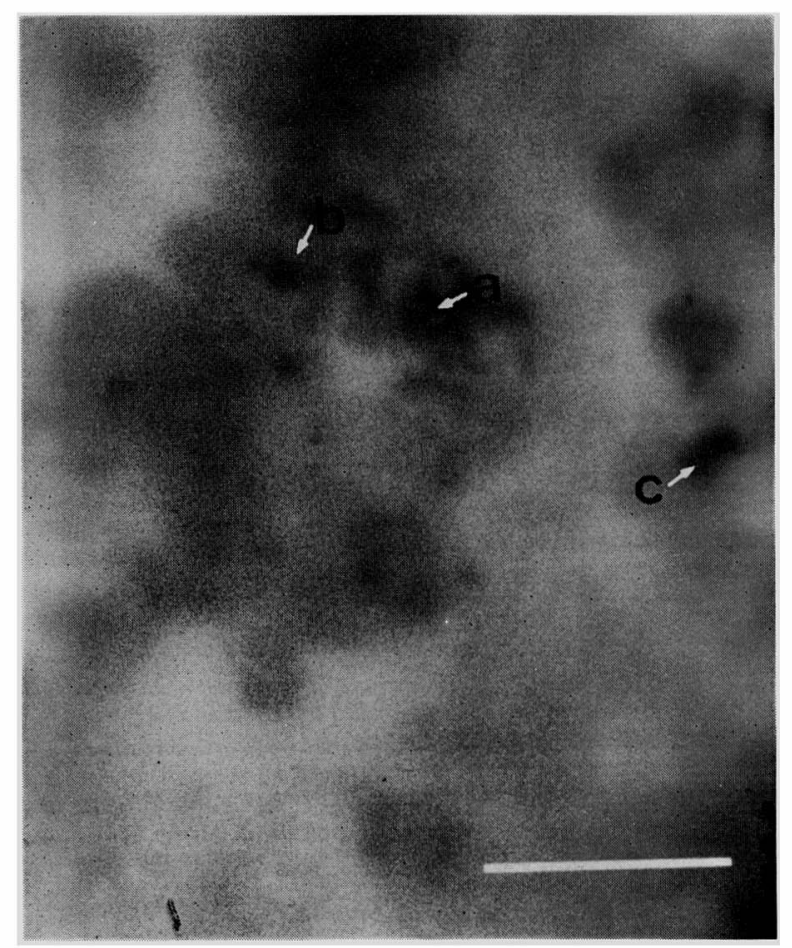

Fig. 10. STEM image of a portion in the cytoplasm of the other macrophage. Electron probe $\mathrm{X}$-ray analysis (Figs. 11-13) was made at three points $(\mathrm{a}-\mathrm{c})$ in this figure. Unstained. $\quad \times 50,000$

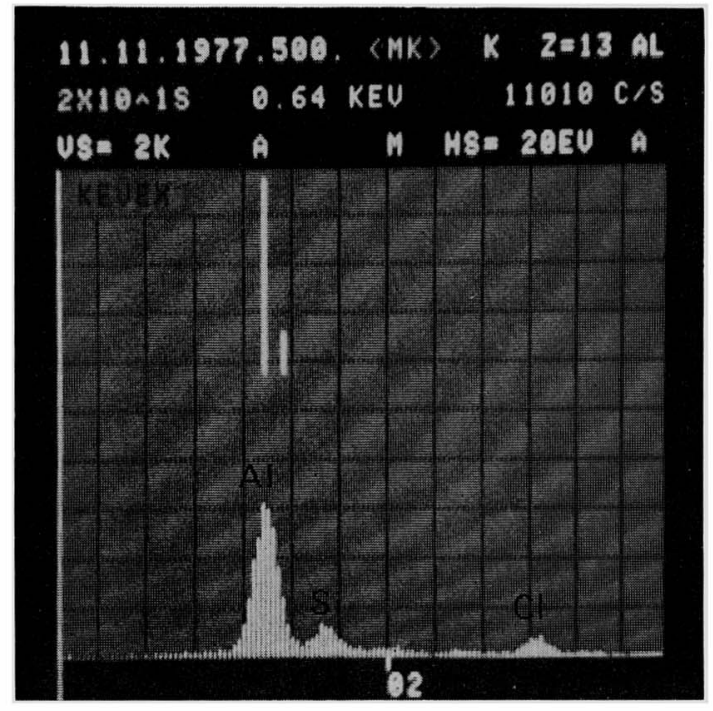

Fig. 11. Spot X-ray energy analysis of (a) in Fig. 10. (Table 1) There are high and low energy peaks for aluminum $(\mathrm{K} \alpha)$ and silicon $(\mathrm{K} \alpha)$, respectively. The small $\mathrm{Cl}$ peak is from the Epon. 


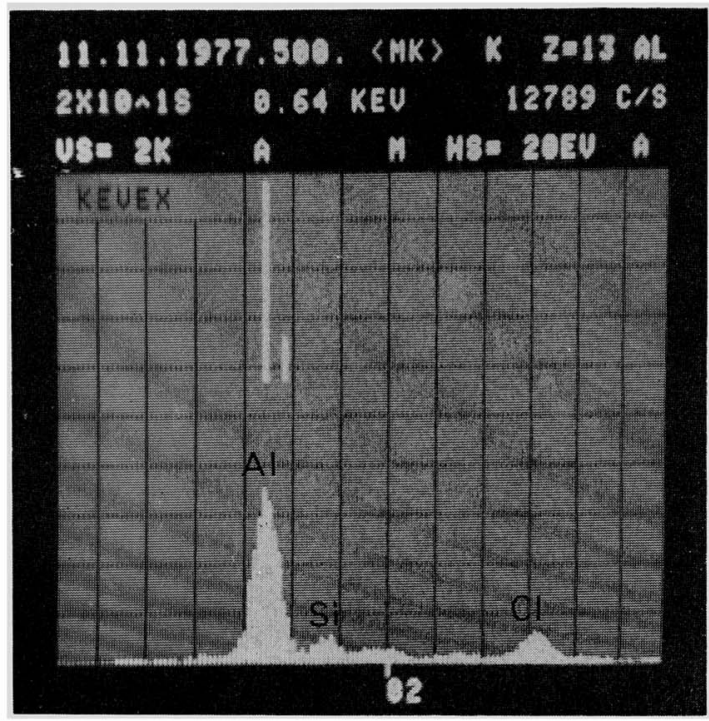

Fig. 12. Spot $X$-ray energy analysis of (b) in Fig. 10. (Table 1) There are high and low energy peaks for aluminum $(\mathrm{K} \alpha)$ and silicon $(\mathrm{K} \alpha)$, respectively. The small $\mathrm{Cl}$ peak is from the Epon.

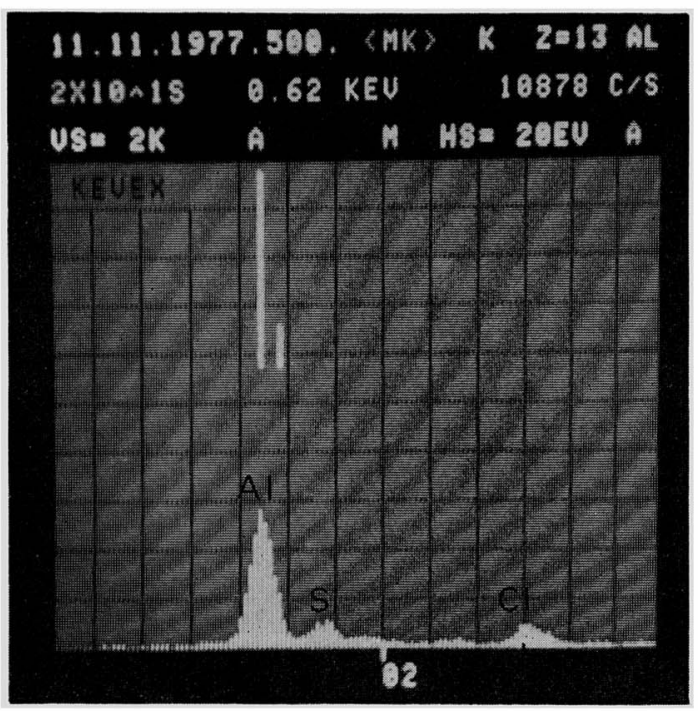

Fig. 13. Spot $X$-ray energy analysis of (c) in Fig. 10. (Table 1) There are high and low energy peaks for aluminum $(\mathrm{K} \alpha)$ and silicon $(\mathrm{K} \alpha)$, respectively. The small $\mathrm{Cl}$ peak is from the Epon. 


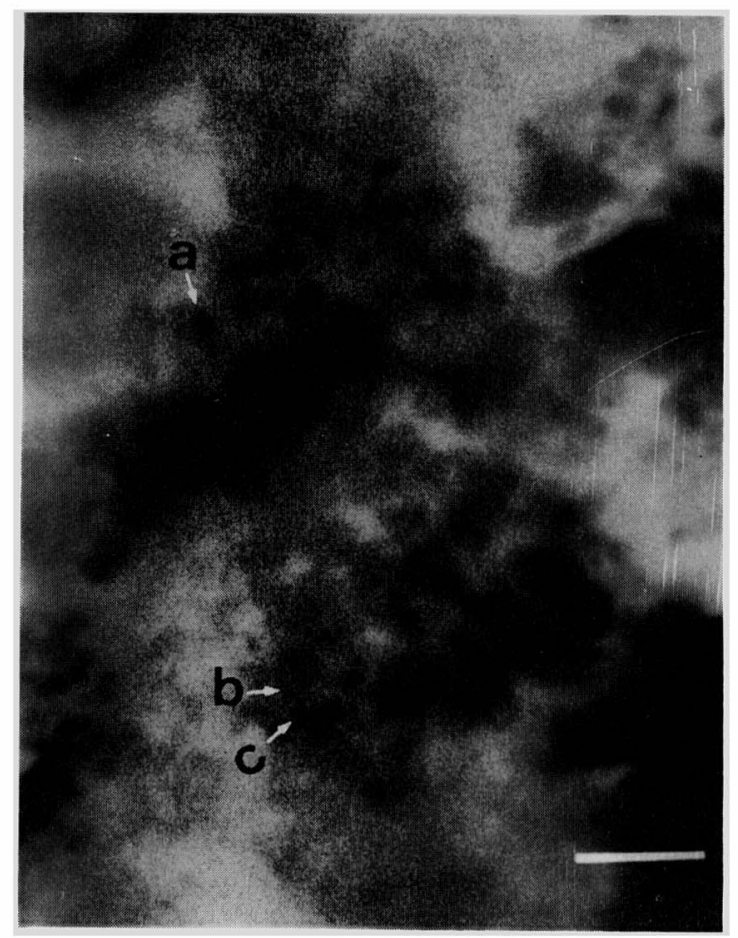

Fig. 14. STEM image of a portion in the cytoplasm of the macrophage. Elemental analysis (Figs. 15-17) was made at three points (a-c). Unstained. $\quad \times 24,000$

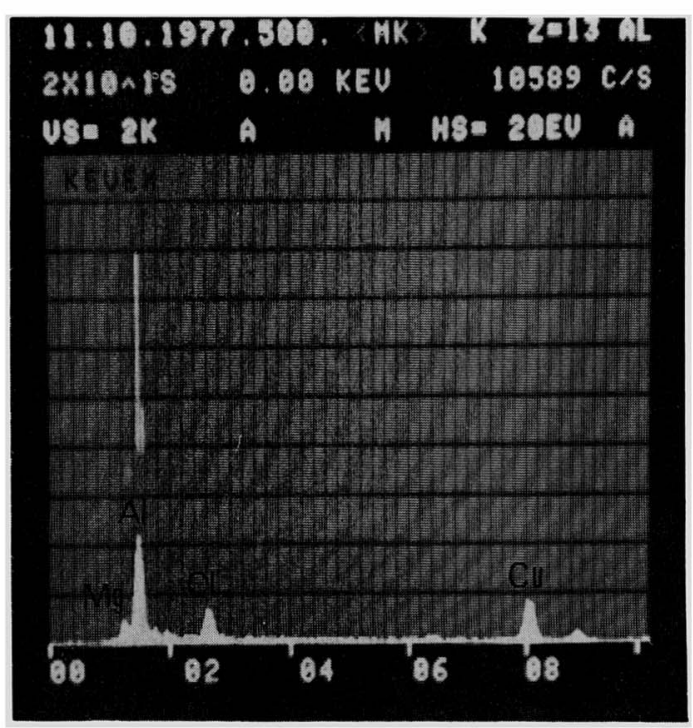

Fig. 15. Spot X-ray energy analysis of (a) in Fig. 14. (Table 2) There is a distinct energy peak for aluminum $(\mathrm{K} \alpha)$. The small $\mathrm{Mg}$ peak is from a mixture and the small $\mathrm{Cl}$ peak from the Epon and the small $\mathrm{Cu}$ peak from the grid. 


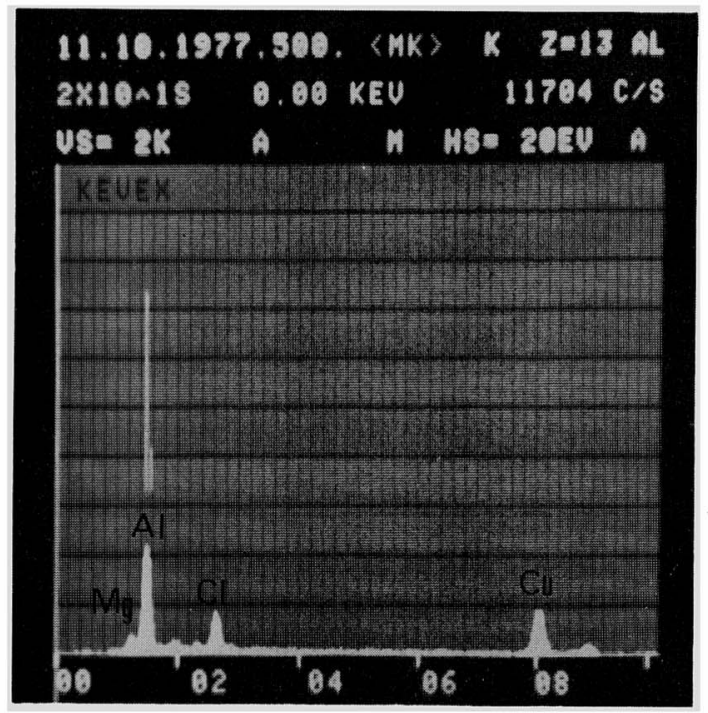

Fig. 16. Spot X-ray energy analysis of (b) in Fig. 14. (Table 2) There is a distinct energy peak for aluminum $(\mathrm{K} \alpha)$.

The small $\mathrm{Mg}$ peak is from a mixture and the small $\mathrm{Cl}$ peak from the Epon and the small $\mathrm{Cu}$ peak from the grid.

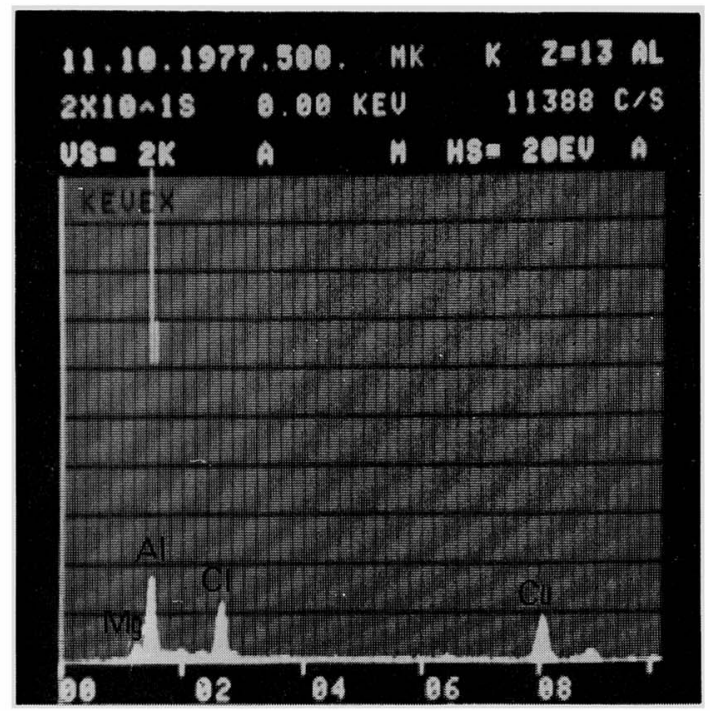

Fig. 17. Spot X-ray energy analysis of (c) in Fig. 14. (Table 2) There is a definite peak fo aluminum $(K \alpha)$.

The small $\mathrm{Mg}$ peak is from a mixture and the small $\mathrm{Cl}$ peak from the Epon and the small $\mathrm{Cu}$ peak from the grid. 
Table 1

\begin{tabular}{l|c|c|c|}
\hline \multicolumn{4}{c}{ X-ray microanalysis of elements in a pulmonary } \\
Epon section. & \multicolumn{2}{c}{$75 \mathrm{KV}, \quad 5 \times 10^{-10} \mathrm{~A}, \quad 20 \mathrm{sec}}$. \\
\hline \multirow{2}{*}{\begin{tabular}{c|c|c|c} 
Elemental \\
Line
\end{tabular}} & $\begin{array}{c}\text { Fig. } 10 \\
\text { (a) }\end{array}$ & $\begin{array}{c}\text { Fig. } 10 \\
\text { (b) }\end{array}$ & $\begin{array}{c}\text { Fig. 10 } \\
\text { (c) })\end{array}$ \\
\cline { 2 - 4 } & \multicolumn{3}{|c}{ Counts $/ 20$ sec. } \\
\hline Al (K) & 3750 & 2849 & 3240 \\
Si (K) & 582 & 591 & 663 \\
back ground & 73 & 59 & 55 \\
\hline
\end{tabular}

Table 2

$\mathrm{X}$-ray microanalysis of elements in a pulmonary Epon section. $\quad 75 \mathrm{KV}, 5 \times 10^{-10} \mathrm{~A}, 20 \mathrm{sec}$.

\begin{tabular}{l|c|c|c}
$\begin{array}{l}\text { Elemental } \\
\text { Line }\end{array}$ & $\begin{array}{c}\text { Fig. 14 } \\
\text { (a ) }\end{array}$ & $\begin{array}{c}\text { Fig. 14 } \\
\text { (b) }\end{array}$ & $\begin{array}{c}\text { Fig. 14 } \\
\text { (c ) }\end{array}$ \\
\cline { 2 - 3 } & \multicolumn{2}{|c}{ Counts /20sec. } \\
\hline Al (K) & 2282 & 2242 & 1814 \\
Si (K) & 294 & 415 & 382 \\
Mg (K) & & 199 & 246 \\
back ground & 58 & 66 & 73 \\
\hline
\end{tabular}

Notes: Relative concentration of silicon contained in control lung tissues was shown to be approximately one-tenth of that in lung tissues of silicotic population $^{5)}$. 